great value in our daily work. At any rate, we should make it a matter of principle to try to be as exact and correct as we can. Therefore, I would take exception, at least for the use of the specialist, to this little instrument which is intended to replace a tuning-fork, shown to-day. Professor Loeb, in a conversation, if my memory serves me right, told me that experiments had bcen carried out under his direction. years ago, with the aid of an instrument similar to the one I have mentioned. If I am not mistaken, the experiments to which Professor Loeb referred were intended to establish facts as to the acuteness of hearing under various conditions. It is important, I think, to consider conditions under which hearing tests are made. I remember that one time when I had overworked myself $I$ thought $I$ heard the clock at 11 p.m. strike twenty-seven times. It was, if I remember correctly, after I was fatigued through study. The time of the day and the other conditions of the patient, I think, should be taken into consideration when a hearing test is made.

Dr. B. A. Randall, Philadelphia-I have the Edelmann tuning-forks and they are very nice, very useful and pretty, and as specious as any that are made, for, like the Politzer acoumeter, they are apt to differ in tone and loudness and other essentials, so that in a dozen you could hardly find two that do not differ. I have not tried to split hairs, but only to get at the diagnostic points that are of value in treatment. So I bave not tried to lay down just what should be the precise limits as to time and distance that the fork should be heard. As to the Galton whistle, I have brought that forward because the prime essential lies in the fact that we are dealing with a closed pipe and must have a definite length and that ler:gth can not be defined if the opening is not rectilinear. Edelmann's new whistle may be as specious in many respects as the set of rods I have, which he said he had made for Kocnig's rods; but they were inaccurate, arbitrarily numbered and what they stood for he could not tell. I have much respect for the good work done on the other side of the water, but the very bad work I have seen cmanating from Edelmann and other men has made me favor the work done on this side of the Atlantic.

\section{EFFECT OF ALCOHOL ON THE NERVOUS SYSTEM, THE MIND AND HEREDITY.*}

ALBERT E. STERNE. A.M., M.D.

Professor of Nervous and Mental Diseases, College of Physicians and Surgeons; Neurologist to the City Hospital, Ete.

INULANAPOLIS, INI).

Alcohol has a twofold effect on the nervous system, a direct or primary, and an indirect or secondary. Either of these may act physiologically, i. e., functionally, or pathologically; i. e., structurally. Either may and does unfold its force upon every part of the nervous system, brain, cord, and peripheral nerves; in fact on every organ and tissue of the body, notably upon the blood-vessels, particularly of the brain, the kidneys and the liver. The subject is too large to render justice to it within the limits of a paper like this, and I shall, therefore, be forced to confine my remarks to a narrow domain.

Upon the nerve tissues alcohol has an acute influence. This can best be studied by experiments on animals, and by the effects shown in fatal poisoning with large amounts of alcohol in persons unused to its influence. Of the ordinary state of acute intoxication, I need not speak. That picture is familiar to all of us.

In a very able paper, Dehio, ${ }^{1}$ some years ago, demonstrated changes in the ganglion cells of the cerebellum produced by acute alcohol poisoning. A year later, Stcwart ${ }^{2}$ confirmed and extended the observations of Dehio, which consisted in the diminution of the chromo-

* Presented to the Section on Nervous and Mentai Diseases, at the Fifty-first Annual Meeting of the American Medical Association, held at Atlantic City, N. J., June 5-8, 1900 .

1. Heinrich Dehio: Experimentelle Untersuchungen über die Veriinderungen der Ganglienzellen bei der acuten Alkoholvergiftung; Centralbl. f. Nervenheilkunde und Psychiatrie, 1895, N. F. 6-11ร.

2. Colin C. Stewart: Influence of Acute Alcohol Poisoning on Nerve Cells; Jour. of Experimental Medicine, vol. i, 1896, p. 623 . phile granules of the nerve cells of the cerebral cortex, the Purkinje cells of the cerebellum, and the large multipolar cells of the spinal gray matter. The importance of these changes is vastly increased in the light of the theory that the ganglionic cells possess certain powers of mobility of an ameboid nature, which permits them to extend and to retract their cell-prolongation to a slight degree, producing normally a contiguity of structure without continuity. I believe in this theory, for it is the only one which explains to me the phenomena of life, both in rest and in activity. Into that, however, I can not enter further at present.

I have in mind a unique, unpublished case which may bear a close relation to the observations of Dehio and Stewart. It is that of a young man who, about one year ago, was referred to me. 'The patient presented a most curious complex of symptoms, which I have nowhere found described, and which I herewith take the opportunity to record.

F. W., white, a farmer, aged 19 years, had up to about seven months previous to my seeing him been quite well, and constantly engaged at work on his father's farm. During a period of perhaps a year before any symptoms had become manifest he had been drinking somewhat, but had never indulged to intoxication. Gradually a general lack of nutrition set in, he began to lose weight and strength, and almost imperceptibly, at first, peculiar spasmodic seizures supervened. These attacks were wholly motor in character, occurring, as the malady developed, more and more frequently until, when he came to my sanatorium, they were almost constant, recurring at the actual rate of about once every two minutes, day and night. During the entire period of the affection the appetite was excellent, no symptoms were shown by any of the internal organs, no sensory changes were manifest, nor were the secretions altered, save that the urine was somewhat scant and perspiration slight. In fact, all symptoms related to the motor nerve sphere, though at no time was there the slightest degree of paralysis noted. The seizures were characterized as follows:

Every few moments the muscles became tense and rigid, apparently all over the body-trunk and limbsface neck, eves, tongue, larynx, esophagus, etc. During the attack. he could usually make voluntary movements, but he could walk, talk, breathe and swallow with difficulty. The facial muscles and masticatory muscles became "set" and the neck stiff. There never was any inclination to opisthotonus, nor the slightest loss of consciousness. No vasomotor signs were present, the cutaneous and pupillary reflexes were normal, but the deep tendon reflexes were somewhat increased. $\mathrm{He}$ suffered no pain whatever, but some muscular soreness existed, doubtless due to the muscular contractions.

At the first examination, I declined to give a positive opinion of his case, but expressed the conviction that the malady would not remain stationary, that it would either prove rapidly fatal, or he would recover under proper treatment within a few weeks, advising careful observation and treatment at the sanatorium. At that time I felt sure I could bar out an hysterical affection of which no symptom was shown. My advice was followed, and the patient remained under my immediate care for nine weeks. During this period he steadily improved under static electricity, massage and the use of tincture of gelsemium, ten drops thrice daily, until complete recovery occurred. The seizures gradually decreased in frequency and intensity until they ceased altogether. I would perhaps not have mentioned this 
case in this connection except for two facts. 1. The only etiologic factor to be elicited was that he had used alcoholic drinks before the affection obtained. 2 . On three separate occasions, when he had almost recovered, friends came to visit him and he indulged in a glass of wine with the result that, each time, the attacks recurred with their former force and frequency, proving to me conclusively that there existed the most direct relation between the seizures and the use of alcohol which produced this peculiar multiple paramyotonic condition. I have never heard of a similar case.

Undoubtedly, many other examples of the toxic character of alcohol and its influence on the nervous system could be cited. I need merely make mention of the analogous states known as delirium tremens, due to the excessive use of spirits containing large amounts of fusel oil; of the ordinary phenomena of acute intoxications in which the loss of inhibitory power in all spheres is of such common occurrence that it is usual to accept the opinion of the stimulating effect of alcohol on mental activity. This opinion I regard as decidedly erroneous. There is a vast difference between increased functional brain power and diminished inhibitory power, but momentarily the apparent effect may be similar.

When we come to speak of the more chronic condition called "alcoholism" we meet with a very different entity. Here can best be seen the effect of the poison on the nervous system, owing to the fact that widespread changes have taken place in the central nervous organs.

of these changes those of the vascular system of the brain are by far the most common. It would appear, therefore, that the effect on the nerve tissue itself is purely secondary, due, in other words, largely to malnutrition of the nerve elements. The alterations in the structure of the artery walls are widespread and frequently reach a high degree, even to obliteration of the lumen of the blood-vessel and consequent softening of the brain tissue. Even a slight degree of textural change in the arterial structure is apt to be followed by an array of symptoms, made up chiefly of those in the motor field, such as tremors, weakness, etc., and those appertaining to the highest functions of judgment, memory and other intellectual faculties.

of the many pathologic conditions supervening on the use and abuse of alcohol through a long period of time, it is surely unnecessary to speak at length. I need merely inention the frequent inflammatory processes of the peripheral nerves termed "alcohol neuritis," and reiterate the importance of the structural alterations of the blood-vessel walls with increased arterial tension, loss of vascular elasticity, consequent infiltration with calcium salts producing arteriosclerosis and endarteritis, which makes the danger of apoplexy lie close at hand. It must be recollected that no healthy blood-vessel ever bursts save and alone as the result of traumatism. Whenever and wherever an artery breaks, except it be diue to injury, the vessel must be diseased. Moreover, no single factor contributes so largely to disease of the blood-vessels as much as the chronic use of alcohol poison. I have already alluded to the psvchic changes of such individuals, to the loss of judgment. memory, and the other intellectual faculties, inducing changes in the products of the brain-the mind and morals. It is this which brings this question into close relation to civic life, which makes it the greatest civic psychosis.

Before speaking of the influence of alcohol on the mind, let me preface by saying that there exists in silmost every case of insanity a well-marked predisposition of the individual to the development of mental disease. It would follow, therefore, that few persons of actually sound condition, anatomically and physiologically, ever fall victims to these affections. Again, it naturally follows that the weaker the inducing cause, the more pronounced should be the tendency toward deterioration. Conversely, it may be said, the more marked the atavistio tendency is, the less will be required to assist in the transition from the realms of sanity to those of mental disease.

Of the minor, practically merely contributing factors may be mentioned overwork, overstudy, emotional effects of an occasional character, the strain of acute diseases, and religious infiuences. You will understand that I nowise underrate the dignity of these elements, whose import is disproportionately increased if they become coincident with the physiologic periods of life.

Among civilized peoples, it has for generations been rightly deemed necessary to segregate the mental sewage of humanity. It should, therefore, be recognized as equally incumbent to thoroughly inquire into the chiefest causes through whose malignant influence these channels are kept full to overflowing. By such investigation, and by the lesson it teaches, can we hope to stem the steadily-if slowly-increasing tide of human forces whose awful effect is best seen in our insane asylums and in their close relations, the penitentiaries.

I have long held to the view that every disease has a basis to start on, and that no so-called "drug habit" forms an exception to this rule. Chronic alcoholism and its sister maladies, like morphinism, develop on a pronouncedly neurotic basis, and it seems to me the lack of success in the treatment of these affections is largely due to the fact that this neurotic element has been neglected. Allow that foundation to remain and the malady recurs. Alcoholism and similar vices belong to the realm of borderland, that great expanse abutting on insanity; and it takes but some slight contributing cause to pass over into the latter.

It has already been intimated that every individual case shows more or less predisposition to deviation from normal mental and moral standards. While the fast is true, the import of this is almost lost in comparison with noxious social and civil influences which are unfolding widespread effects. I fully realize the importance of this assertion, when I say that society and its social laws, civil life and its license are almost wholly responsible for the overcrowded condition of the insane hospitals and prisons, homes of the mental and moral degenerates. A charge so serious should be well founded. I shall seek to justify it.

The evolution of the human race is but the evolution of the individuals composing it. To evolve a perfect race, perfect individuals must be evolved. No nation passes into decadence and degeneracy save through the decay and degeneration of its components. Such truths must be quite apparent. Let us ask ourselves, then, what elements are mainly at work in the production of individual mental and moral deterioration, for the time being leaving entirely unheeded the many minor incidental factors.

The main causes I have already stigmatized as social and civic evils. To these I count habits of all kinds, yet most of all the use of alcoholic drinks; to these I count lack of hygienic principles which permits the gross spreading of diseases; to these I count. most important of all, the total disregard shown throughout the world to the bringing into it of human beings unfit to live. Daily, thousands of poor bundles of humanity are born into life with infinitely less concern 
for their future weltare and perfection than is exercised in the breeding of our most common cattle.

Alcoholism is a disease, an enormously frequent one, whose ravages are tenfold worse than any other known to me, for unlike them its effects are not arrested by death. It is neither my purpose nor my desire to inveigh against the use of alcohol, but to bring to your notice the malignant effect of its abuse. You must recognize alcoholism in its chronic form as a disease. It is attended by a huge array of symptoms. Suffice it to say that chief among them is the material change in the structure of the blood-vessels, notably in the brain and kidneys, and that secondarily, and sometimes primarily, minute alterations in the intrinsic nature of the brain cells occur, which ultimately bring about total wreckage, physical, mental and moral. Unfortunately, there is nearly always a marked tendency of neurotic character present which permits the development of any vicious habit, and this tendency is decidedly transmissible and augments by transmission: The appalling truth of the latter statement is amply verified by experience with the innocent offspring of alcoholists. Go into our homes for feeble-minded, enter the reformatories for boys and girls. There, surely, personal histories repeat themselves. There, surely, the traits and tendencies of ancestry can best be studied and the secrets of hereditary burdening and bondage be learned.

The influence of heredity has never been questioned in the domain of psychology, normal and perverted. Yet it must be plain that to speak of heredity means simply to accentuate certain phases of transmission, good and bad. With a few specific exceptions, disease is never handed down to progeny from the ascendants. As we inherit peculiar quantitative traits, so we assume peculiar qualitative elements from those to whom we owe existence. As children inherit looks and features so, too, they show certain characteristics of disposition, which, when they become predominant, form a predisposition or tendency in the one or other direction. That this predisposition can be checked or fostered is a wellknown fact to every student of evolution; it is even known to every breeder of livestock who studiously seeks to eliminate the bad and foster only the good qualities of sire and dam. Shall we, human beings, gifted beyond all other forms of animal life, be less faithful in the pursuit of developing ideal offspring? Yet, as a rule, that is exactly what is being done. Mental cripples. crowd our asylums for the insane, moral ones constitute our criminal classes, and these crowd our prisons and reformatories. The two are closely related and both are manifestly the results of existing social and civil principles. I most earnestly believe that the factors I have spoken of are the main causes -aided, it is true, by many of the lesser degree-which make it necessary to maintain the many institutions for the care of the insane and the imprisonment of the criminal, all for the sake of protection to the welfare of the general public.

In conclusion, let me emphasize by repetition the import of the foregoing. As I frequently tell my students, "it is not the man who occasionally becomes intoxicated who gets into trouble, but the man who drinks much and never gets drunk, or he who is nearly always drunk, that becomes a candidate for disease." His are the blood-vessels that early grow less elastic and more brittle, his are the chances for apoplexy and consequent infirmity, his are the weakened will-power and moral force, his are the nerve tissues that show slight vitality. His, again, are the offspring of stunted intellectual mold, who lack the ennobling qualities of men and women, but show to a marked degree the signs of mental and moral and physical degeneracy, which make them easy victims of epilepsy, imbecility and idiocy on the one hand, and, on the other, gives them the inherited and acquired right to a berth in the insane hospitals, the jails and the penitentiaries.

If but the true import of the alcohol question were understood and a proper conception of the effect of alcohol on the physical and mental qualities were gained, I believe few generations would pass before we would find in place of our institutions for restraint and punishment, hospitals for the care and cure of a class of patients more ill often than those whom we generally regard as sick or diseased.

\section{DISCUSSION.}

Ir. A. J. Pressey, Cleveland, Ohio.-The Doctor has covered the ground very completely, and I would say "amen" to what he has said.

Dr. G. W. Drake, Hollins, Va.-I would like to ask the speaker to tell us the difference between the effects of pure alcohol diluted, and the various preparations of alcohol in the form of whisky, brandy, etc. I have never had any experience, but $I$ always had a desire to know whether it is more injurious or dangerous to use pure alcohol diluted or whisky or brandy. I notice he spoke of fusel-oil. Alcohol has the advantage of not containing it. I am only entering a protest against the idea that the mind is capable of becoming insane, drunk, intoxicated or affected by any material disease. The brain may become diseased, but the mind is not subject to any effect from material objects.

Dr. Albert E. Sterne, Indianapolis, Ind.-I only wish to apologize to the Section for cutting up my paper the way I did. I have taken the standpoint that nobody ever forms il habit. except from a neurotic predisposition. It always has a basis to develop on, like any other disease, and the use of molphin and alcohol must be looked upon in its chronic form is a disease. Whether mind or matter is diseased is immaterial, it does not make much difference, and so far as the mind being capable of disease, that is something which I do not feel able to speak upon. My conception of mind differs from that of my colleague.

As regards the use of small doses of alcohol and aloohol in any form, I may simply reply that a poison is a poison no matter how it is taken. Irereury is mercury, no matter in what form we give it. The more refined the spirits, the less side issue will prevail, but the intrinsic effects of alcohol are never altered. There is a vast difference in the use of alcohol, say in the form of whisky, and beer as used in Germany. In the use of beer there is a mechanical efiect observed. The large quantity of fluid dilates the blood vessels, and this insult to then renders them less elastic and, in addition to that, there is a large nutritive element which, if it is taken up as nutrition, means more work for the heart, because the new tissue must be nourished. You are overburdening the organ and, therefore, the effect on the ventricle is weakening; this is seen in beer drinkers, where it is not seen in alcohol drinkers or morphin habitues.

The question is entirely too large for me to cover in such a manner as this. I took it for granted that the alterations were all well known to members of this section. I have spoken to several neurologists about the peculiar case reported, and they have not been able to throw any light on it. or add to my coneeption of it.

Accidental Vaccination.--Apropos of a case of accidental vaccination reported in Tre Journel of March 2 (p. 584), another reported in The Lancet of Febluary 23 is of interest. It was that of a man of 45, who, on Sept. 14. 1900, received a slight scratch on the outer angle of the right eye. A week previously his child had been vaccinated, and, in caring for the child at night, during the mother's illness, the seratch became inoculated from the child's arm. The man's eye became very painful and irritable, with symptoms of soptic poisoning. 